\title{
La psicología moral de Sócrates
}

Daniel Graham

Brigham Young University - Provo, daniel_graham@byu.edu

Follow this and additional works at: https://scholarsarchive.byu.edu/facpub

Part of the Other Philosophy Commons

\section{Original Publication Citation}

"La psicología moral de Sócrates." Theoria, revista del colegio de filosofía de la FFyL de UNAM 15-16(2003): 53-69.

\section{BYU ScholarsArchive Citation}

Graham, Daniel, "La psicología moral de Sócrates" (2003). Faculty Publications. 3773.

https://scholarsarchive. byu.edu/facpub/3773 


\title{
La psicología moral de Sócrates
}

\author{
Daniel W. Graham
}

Os estimo y os amo, hombres de Atenas, pero obedeceré al dios en vez de [obedeceros] a vosotros, y mientras respire y tenga vida, no dejaré de filosofar, exhortando y desafiando a cualquiera de vosotros con quien me encuentre, diciéndole de la manera que acostumbro: "Hombre excelente, tú que eres ciudadano de Atenas, la ciudad más grande y la más famosa por su sabiduría y su poder, ¿no te avergüenzas de dedicarte a amontonar dinero, gloria y poder, sin prestarle ninguna atención a la sabiduría, a la verdad y al mejoramiento de tu alma?" Y si alguien protesta y dice que sí se preocupa, no lo dejaré de inmediato ni me iré, sino que le preguntaré, lo indagaré, y lo probaré. Y si encuentro que no ha logrado la virtud, sino sólo finge que sí, lo culparé por pensar que lo más valioso tiene menor importancia, y que lo que es menos importante tiene más valor. ${ }^{1}$

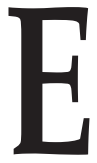

n este sorprendente pasaje de la Apología, Sócrates se presenta como reformador de la moralidad, llevando su mensaje de que la virtud es más importante que cualquier otra cosa al hombre común y corriente. "Exhorta" (parakeleuomenos), "desafía" (endeiknumenos), y "culpa" (oneidiō) al desafortunado ateniense que encuentra. Mas cuando consideramos el retrato que hace Platón de Sócrates en acción en las calles de Atenas, no vemos que Sócrates se entregue a ninguna de estas actividades. Claro que interroga a su compañero de discusión acerca de la virtud, pero usualmente se fija sólo en la definición, no en su práctica o su adquisición. Examina y refuta las definiciones ofrecidas, pero nunca alcanza la lección moral que su interlocutor podría obtener de la conversación. Esperamos una lección mo-

\footnotetext{
${ }^{1}$ Platón, Apología de Sócrates, 29d-30a.
} 
ral, y en cambio recibimos una lección en lógica; esperamos una exhortación, y lo que oímos es dialéctica.

¿Qué es lo que Sócrates se propone? ¿En verdad anda tras la metaética más que tras la ética? ¿Acaso está buscando, tal vez en vano, los fundamentos de una teoría ética? ¿Confunde la teoría con la práctica? ¿Existe alguna conexión entre la definición de la virtud y la práctica del élenchos, por una parte, y la práctica de la virtud y el vivir la vida moral, por otra? Ésta es tal vez la cuestión más básica y más persistente en el estudio de Sócrates. Por lo menos desde el tiempo de Aristóteles, y, según yo voy a sugerir, aun antes, en Platón, la teoría moral de Sócrates ha sido criticada por ser excesivamente intelectual y por estar demasiado alejada de los hechos de la vida moral -ta phainomena, en los términos de Aristóteles. En esta ocasión voy a examinar de nuevo la tesis socrática de que la virtud es conocimiento (sección I) e intentaré demostrar cuán radicalmente diferentes son las asunciones de su psicología moral de las nuestras (II); luego propondré un modelo del alma para ayudar a explicar su teoría (III), y mostraré cómo el modelo puede ayudar a resolver ciertos rasgos paradójicos del método y teoría de Sócrates (IV). ${ }^{2}$

\section{Virtud es conocimiento}

El único diálogo en que Platón deja que su personaje Sócrates vaya más lejos en su búsqueda de una definición es el Protágoras. Persistiendo a través de algunas desviaciones causadas por Protágoras o sus compañeros sofistas, Sócrates logra una definición del valor. Después de refutar varias definiciones, Sócrates llega a la siguiente: “¿Es la valentía sabiduría acerca de las cosas peligrosas y no peligrosas?"3

Aquí Protágoras guarda silencio, reconociendo que el argumento ha contradicho su posición anterior. La valentía es sabiduría, o, para emplear un término equivalente del vocabulario de los diálogos socráticos, conocimiento. ${ }^{4}$ Dos páginas antes, Sócrates ha dado la premisa necesaria para deducir su

\footnotetext{
${ }^{2}$ Los estudiosos de Sócrates emplean un gran número de enfoques hoy en día. Aquí voy a asumir que (a) hay posiciones filosóficas de Sócrates y Platón en los diálogos (es decir, que los diálogos no son sólo exploraciones de posiciones posibles) (b) los diálogos tempranos de Platón proporcionan la mejor evidencia para una reconstrucción de Sócrates, pero (c) Platón no está de acuerdo siempre o necesariamente con lo que el personaje "Sócrates" dice. Tengo una gran deuda con la obra de Gregory Vlastos, como se ve en (a) y (b), pero me desvío de sus asunciones metodológicas en (c).

${ }^{3}$ Platón, Protágoras, 360d.

${ }^{4}$ Sócrates alterna entre sophía, sabiduría, 350c4, 360d2, y epistēmēe conocimiento, 352c1, 357b4. Compárese el Eutidemo, en el cual epistēmē, sophía, y phronēsis se
} 
definición: todo el mundo quiere su propio bienestar: "Nadie busca males voluntariamente, ni cosas que cree que son males; ni tampoco es esto, como parece, consistente con la naturaleza humana, querer buscar cosas que se creen malas en vez de buenas". ${ }^{5}$

Si en verdad es un principio de la naturaleza humana que todo el mundo busca lo bueno y evita lo malo, la valentía y todas las demás virtudes consistirán en tener el conocimiento pertinente de lo bueno y lo malo en el ámbito correspondiente. La valentía será un conocimiento de lo que es peligroso y lo que da protección ante el peligro. La prudencia será un conocimiento de cuáles placeres son benéficos y cuáles dañinos; la piedad será un conocimiento de cuál relación con los dioses es buena y cuál mala, etcétera.

Existen, sin embargo, problemas bien conocidos acerca de lo que debería ser un relato sencillo acerca de la virtud. Discutiré brevemente cuatro de los muchos obstáculos potenciales.

1. En el Protágoras, Sócrates enuncia la tesis que la virtud es conocimiento junto con otra: que la virtud no se puede enseñar. ${ }^{6} \mathrm{Al}$ final del diálogo, cuando parece que Sócrates puede establecer su definición, de repente finge darse cuenta del hecho de que su primera tesis no es consistente con la segunda: si la virtud en verdad es conocimiento, debería ser enseñable. Protágoras se excusa de una discusión más larga, y nosotros nos quedamos con el problema sin resolver, quedando abierta la posibilidad de que las dos tesis sean irreconciliables, o por lo menos de que sea necesario hacer algunas importantes modificaciones o retractaciones a una tesis, o a ambas.

2. En el Laques, Nicias ofrece una definición de la virtud que es muy parecida a la de Sócrates en el Protágoras. ${ }^{7}$ Pero en esa ocasión, Sócrates ataca la definición y la refuta. Lejos de recibir una nueva consideración y una elaboración y defensa más amplias, la definición se rechaza como inadecuada.

3. En el Cármides, Sócrates examina varias definiciones de sōphrosunēe, prudencia o dominio de sí mismo, que parecen ser comprendidas según el modelo socrático. La prudencia es conocimiento de sí mismo, o conocimiento de lo bueno y lo malo, o conocimiento del conocimiento. ${ }^{8}$ En cada caso la definición es derrotada, y al final Sócrates parece no estimular un examen más profundo de estas definiciones socráticas, en un sentido amplio. ${ }^{9}$

usan sin distinción dentro del espacio de unas pocas líneas: 281a8, b1, b3, 282a4; 281b6, d8, e4, 282c1, c8; 282b6, d8, respectivamente.

5 Platón, Protágoras, 358c-d.

${ }^{6}$ Ibid., 319b y ss., 320b, repetido en 361a-b.

7 Platón, Laques, 195a y ss.

${ }^{8}$ Platón, Cármides, 164d, 166c, 167a y 174b.

${ }^{9}$ Resumen de críticas consecutivas, Cármides, 175 b y ss. 
4. Más allá o detrás de estos conflictos y estos fracasos particulares por presentar una defensa coherente de la tesis que la virtud es conocimiento, está el desafío familiar, pero bien real, de que la teoría parece contradecir nuestra experiencia. Simplemente no hay ningún tipo de conocimiento que una persona pueda tener, el cual pudiera garantizar que su comportamiento sea correcto. Con frecuencia no conseguimos vivir de acuerdo con nuestros propios ideales, incurriendo en un error conocido como debilidad de la voluntad, akrasia. ¿Cómo puede tener éxito una teoría que pasa por alto el fenómeno del incumplimiento de las propias convicciones morales?

No obstante los problemas, hay fuertes indicaciones de que Sócrates toma muy en serio la tesis de que la virtud es conocimiento.

1. La paradoja de que la virtud es conocimiento, pero no se puede enseñar, es prominente no sólo en el Protágoras sino también en el Menón, ${ }^{10}$ un diálogo que parece representar una transición a una manera más platónica de proceder. Pero el solo hecho de que esta paradoja siga teniendo un papel importante indica su posición como dato, tal vez como un caso particular que se pone a prueba, y al que una teoría adecuada (de Platón) da solución.

2. Aunque una definición parecida a la de Sócrates en el Protágoras es refutada en el Laques, Nicias introduce la definición que él defiende precisamente diciendo que ha oído algo semejante del propio Sócrates. ${ }^{11}$ Aquí hay dos posibilidades: a) Platón alude al Protágoras, y b) alude a una definición bien conocida que todo el mundo atribuye a Sócrates. ${ }^{12}$ Ambas posibilidades no son mutuamente excluyentes. Tanto según la lectura literaria (a) como según la histórica (b), la definición del Protágoras parece ser importante y digna de mayor atención. No es simplemente una construcción ad hoc o ad hominem introducida para preparar la peripeteia del Protágoras.

3. La teoría fuertemente criticada en el Cármides encuentra un sólido apoyo en otros diálogos. En el Critón, por ejemplo, Sócrates da una respuesta sorprendente a la declaración que la mayoría de la gente puede hacer gran daño con sus opiniones: “¡Ojalá y pudiera la mayoría hacer el mayor de los males, Critón, porque entonces podría hacer el mayor bien, lo que sería mara-

${ }^{10}$ La cuestión inicial del Menón es si se puede enseñar la virtud, 70a. Se contesta con base en una hipótesis, $87 \mathrm{~b}$-c y $98 \mathrm{~d}$; pero ya que parece que la virtud no se puede enseñar, no puede ser conocimiento, 99a. El problema de si se puede enseñar la virtud se pone también en el Eutidemo, 282c.

11 "Muchas veces te he oído diciendo que cada persona es buena en las cosas en las cuales es sabia, y en las cosas en las cuales es ignorante, es mala" (Platón, Laques, $194 d)$.

${ }^{12}$ Como por ejemplo Aristóteles lo haría mas tarde (Aristóteles, Ética nicomáquea, $1144 \mathrm{~b} 28-30)$. 
villoso! Pero en realidad los más no pueden hacer ni lo uno ni lo otro: no pueden hacer a una persona ni sabia ni tonta; sólo actúan por casualidad". ${ }^{13}$

Sócrates presupone que hacer el bien es aumentar el conocimiento o la sabiduría; hacer el mal es privar de conocimiento o sabiduría. La virtud debe ser conocimiento, o algo muy parecido. Por cierto que Sócrates parece asumir que el poder de hacer el mayor mal es coextensivo con el poder de hacer el mayor bien; y que no hay razón para preocuparse de alguien que tiene ese poder. ¿Por qué no? Probablemente por la razón dada en el Protágoras: todos naturalmente buscamos lo bueno y evitamos lo malo. En el Eutidemo, en un diálogo dentro de un diálogo en el cual Sócrates trata demostrar cómo debe proceder un examen, arguye que sin conocimiento o sabiduría, emplearemos mal cualquier bien (no moral) que tengamos; de aquí, “¿Cuál es el resultado de nuestra discusión? ¿Acaso puede ser otra cosa que esto: que de las demás cosas, ninguna es buena ni mala, mientras que de estas dos, la sabiduría es buena, la ignorancia es mala?"14

La única cosa intrínsecamente buena es la sabiduría o el conocimiento; la única cosa intrínsecamente mala es la ignorancia.

4. El hecho que la definición socrática de la virtud parece ser contraria a la intuición impresionó también a sus intérpretes antiguos y a sus críticos. Claro, es este rasgo el que Aristóteles señala como motivo de sus críticas en el libro séptimo de la Ética nicomáquea. Y él basa sus críticas de Sócrates en la declaración del Protágoras, de que el conocimiento no es algo que se arrastre como un esclavo, sino que es autosuficiente para controlar la acción. ${ }^{15}$ Evidentemente el Protágoras es el locus classicus para el intelectualismo socrático. Sin importar cuán perversa o irrazonable nos parezca a nosotros la doctrina, el convencimiento de que el Protágoras expresa la doctrina misma de Sócrates se remonta a Aristóteles. Y, según yo voy a sugerir más tarde, llega hasta Platón. Así, tenemos razones para considerar que las doctrinas del Protágoras contienen los principios básicos de Sócrates y que constituyen la fuente primaria de su psicología moral.

\section{Intelectualismo y voluntarismo}

Hasta aquí hemos usado el término "intelectualismo" como título general para la posición de Sócrates, sin explicación ni elaboración -como hace la mayo-

13 Platón, Cármides, 44d.

${ }^{14}$ Platón, Eutidemo, 281e.

${ }^{15}$ Cf. Aristóteles, op. cit., 1145b22-27, aludiendo a Protágoras, 352b-c y repitiendo cinco palabras de Platón. 
ría de los comentaristas. Pero para apreciar su posición es necesario que comprendamos qué clase de teoría es, y que la pongamos en contraste con el tipo de teoría que acepta la mayoría de los filósofos morales modernos. Para comprender el intelectualismo y su teoría rival, debemos postular dos facultades o actividades del alma o la mente: el intelecto o la razón, de una parte, y el deseo, las pasiones, o la voluntad, de otra. ${ }^{16}$ De acuerdo con el intelectualismo, el intelecto determina las metas del individuo con base en lo que el intelecto juzga que es lo mejor. Así, si doy dinero a los pobres, lo hago porque juzgo que esa acción es la mejor. Si me rehúso a dar limosnas y ahorro mi dinero, igualmente lo hago porque juzgo que ésa es la mejor acción. Deseo lo que es mejor porque es mejor. Mis deseos son determinados por la razón o el intelecto.

La agradable consecuencia de esta teoría es que hace a los seres humanos agentes racionales. No existen acciones irracionales, aunque algunas parezcan irracionales a otros. Cualquier cosa que hagamos, la hacemos por una razón, aunque ésta pueda ser, desde un punto de vista independiente, una mala razón. La conducta autodestructiva parece proporcionar un contraejemplo a la teoría, porque hacerse daño a sí mismo es irracional. Pero el intelectualista puede buscar una explicación racional: hacerse daño a sí mismo, por ejemplo, el alcoholismo, o incluso el suicido, puede ser visto por el agente (por equivocado que esté) como el menor de dos males.

La teoría alternativa al intelectualismo es el voluntarismo: la teoría de que la voluntad (los deseos, las pasiones) determina las metas del agente. Según esta teoría, por lo menos en su formulación más austera, el intelecto no aporta nada a la motivación del individuo, proporcionándole solamente un cálculo de cómo conseguir los objetos deseados. Podemos observar el contraste entre las dos posiciones en dos formulaciones de los puntos de vista respectivos. En el Protágoras, Sócrates defiende el intelectualismo:

La mayoría piensa así acerca del conocimiento: que no es fuerte ni capaz de dirigir o gobernar... sino que muchas veces, aun cuando está presente en un hombre, no lo gobierna, sino que esto lo hace otra cosa: ahora la pasión, ahora el placer, ahora el dolor, a veces el amor, muchas veces el miedo; muchos conciben al conocimiento como si éste fuera un esclavo arrastrado por todas las pasiones. ¿Es ésta también tu opinión, o lo consideras como algo bello y capaz de gobernar

16 Es bien conocido que el griego no tiene una palabra para "voluntad", pero Aristóteles tiene una teoría elaborada del proceso de decidir, que él llama elección, prohairesis (Aristóteles, op. cit., III.2). Sobre el concepto griego de voluntad, véase Albrecht Dihle, The Theory of Will in Classical Antiquity. Berkeley, Universidad de California, 1982. 
al hombre, de modo que si éste sabe lo que es bueno y malo, no será forzado por ningún otro poder a hacer ninguna otra cosa de lo que el conocimiento ordene, y la sabiduría se bastará a sí misma para dirigir al hombre? ${ }^{17}$

Por supuesto, Sócrates prefiere la segunda teoría, y quiere que Protágoras esté de acuerdo. Contra esta teoría, uno de los defensores más francos e influyentes del voluntarismo en el periodo moderno declara: "La razón es, y debe únicamente ser, la esclava de las pasiones, y jamás puede aspirar a otro puesto que el de servirlas y obedecerlas". ${ }^{18}$

David Hume, empleando la misma imagen que Platón veinte siglos antes (¿a propósito?) declara que la razón es esclava de las pasiones. Pues es solamente una facultad calculatoria: no tiene ningún poder para incitar o mover al alma a la acción. Las pasiones, por su parte, son instintos que incitan al alma a emprender una acción para lograr una meta aprobada por la pasión dirigente.

Según el voluntarismo, el agente humano no es un agente racional, sino esencialmente un animal irracional movido por instintos y apetitos. La racionalidad interviene únicamente en el cálculo de los medios conducentes a un fin, y tal vez, en niveles superiores, en el cálculo de cuáles objetos se pueden obtener y cuáles no. En cuanto que esta teoría es compatible con una concepción pesimista de la naturaleza humana, explica con facilidad la debilidad de la voluntad y las deficiencias morales: los seres humanos en realidad no están motivados por ideales y deberes, sino por apetitos y pasiones, los cuales están dispuestos a irrumpir y controlar al agente.

Aunque una historia de las teorías morales no cabe en los límites de este trabajo, vale la pena observar que, en general, el intelectualismo fue la teoría dominante durante la antigüedad. A pesar del hecho de que Platón y Aristóteles criticaron a Sócrates, sus propias correcciones no los llevaron demasiado lejos de la teoría de aquél. Los dos pueden conceder que, en cierta manera, la virtud es conocimiento. ${ }^{19}$ Un momento crítico aparece en san Agustín, quien meditando en su pasado pecaminoso se dio cuenta de que cuando joven había robado peras del árbol de su vecino, no porque buscara

${ }^{17}$ Platón, Protágoras, 352b-c.

${ }^{18}$ David Hume, $A$ Treatise of Human Nature, II.3.3.

${ }^{19}$ En la alegoría de la caverna (Platón, República, vII, $514 a$ y ss.), Platón reconoce como consecuencia que los gobernantes iluminados tendrán conocimiento (por haberlos visto antes) de los valores genuinos cuyas sombras aparecen abajo (ibid., 520c). La tentativa de Aristóteles de responder a la tesis de Sócrates de que no hay akrasía, debilidad de la voluntad (Aristóteles, op. cit., VII.2-3), no cambia mucho la teoría socrática (1147b14-17). 
algún bien con su acción, sino precisamente porque era un acto malo. ${ }^{20} \mathrm{La}$ experiencia de sus propios pecados contradijo siglos de la ética clásica. En el periodo moderno el gran poder de la voluntad, a veces infinito, ha sido acentuado por Descartes, Hume, Kant, Schopenhauer y Nietzsche, y en general el fondo judeo-cristiano del hombre caído aseguró que el voluntarismo en alguna de sus formas haya sido la teoría dominante.

Es difícil para nosotros apreciar el atractivo del intelectualismo, precisamente porque es tan ajeno a nuestra manera moderna de pensar. Asumimos que no estamos gobernados por una visión de lo bueno, o si alcanzamos una concepción idealista del mundo, lo hacemos con dificultad y contra los deseos constantes de nuestras pasiones. La tesis que la virtud es conocimiento parece ser obviamente falsa: ¿qué clase de conocimiento pudiera asegurar que nuestra conducta sea la correcta? Pero la teoría de Sócrates no es ingenua ni apresurada. Las paradojas que introduce sugieren que debajo de la superficie hay una compleja teoría. Necesitamos un modelo para comprender las declaraciones diversas y aparentemente contradictorias que hace Sócrates a favor de su teoría.

\section{Un modelo del alma}

Puesto que la voluntad está determinada por el intelecto, no es necesario preocuparnos de la voluntad. Lo importante es la manera de funcionar, o al menos el contenido, del intelecto. A veces se mantiene que Sócrates no tiene ningún modelo del alma, ${ }^{21}$ y es verdad que en los diálogos socráticos de Platón, Sócrates no propone formalmente ningún modelo. Pero tal vez valdrá la pena presentar las asunciones de Sócrates en una forma relativamente concreta. Yo propongo un modelo muy sencillo. El intelecto es como un conjunto de proposiciones. Algunas tienen que ser verdaderas, algunas pueden ser falsas. Incluidas en el conjunto están todas las proposiciones necesarias para evaluar correctamente las situaciones morales. Las proposiciones pueden ser identificadas con las creencias individuales. Claro que alguna capacidad de razón debe estar presente también, para poder usar las proposiciones. Pero para todo efecto y propósito, podemos suponer que el intelecto no es más que una máquina para hacer deducciones lógicas a partir de las proposiciones residentes en el alma.

${ }^{20}$ San Agustín, Confesiones, II.4, 6 y 8.

21 Vlastos explica que el Sócrates de los diálogos tempranos no comparte la concepción del alma tripartita de los diálogos medios de Platón (Gregory Vlastos, Socrates, Ironist and Moral Philosopher. Ithaca, Universidad de Cornell, 1991, p. 48). 
La condición del alma se puede determinar por el estado lógico del conjunto de proposiciones, de nuevo muy simplemente. Una de dos: o el conjunto de proposiciones es consistente consigo mismo o no lo es. La consistencia es buena, la inconsistencia es mala. Suponemos que la capacidad para hacer inferencias lógicas no varía de una alma a otra.

La indicación más obvia de que un alma es mala (inconsistente) será que la persona que es dueña de esa alma hace declaraciones contradictorias. Las contradicciones en la conclusión resultarán de contradicciones en las premisas. Cualquier declaración contradictoria de una persona será prueba prima facie de una falla en el alma, es decir: una prueba de que se posee creencias contradictorias. Cualquier discrepancia entre los principios morales declarados de una persona y su comportamiento será una señal de que hay también conflictos lógicos entre sus creencias. Pues según el intelectualismo, los actos del individuo resultan del razonamiento del intelecto. La discrepancia entre los principios de la persona y su comportamiento se llama generalmente "debilidad de la voluntad" (akrasia). Según el modelo proposicional del alma, no hay tal cosa como la debilidad de la voluntad -o en otros términos, el fenómeno de la debilidad de la voluntad puede ser desechado- pues no es más que un síntoma de una condición patológica, a saber, de la incompatibilidad lógica de las creencias de una persona. Por ejemplo, yo digo que un soldado debe ser valiente, enfrentar al enemigo, y obedecer sus órdenes. Pero cuando estoy en campaña como soldado y ciudadano frente al enemigo, tiro mi escudo y huyo. Yo digo que el deber para con la patria es el valor supremo, pero en lugar de, o además de esta creencia, también creo que la muerte es el mayor mal. ${ }^{22}$ Que tengo esta creencia se muestra por mi conducta, la cual deriva de algunas de las creencias que tengo (aun si no de todas).

Podemos comprender esta concepción por contraste con el modelo platónico del alma, que se desarrolla en el libro IV de la República. Platón se toma la molestia allí de aplicar la ley de no-contradicción al alma. ${ }^{23} \mathrm{Si}$ yo digo que no debo comer, pero como de todos modos, hay un conflicto entre mis palabras y mis actos. Dado que predicados incompatibles no pueden pertenecer a la misma cosa de la misma manera y al mismo tiempo, resulta que hay una parte de mí que quiere comer y otra parte que quiere no comer. La contradicción se convierte en prueba prima facie de que hay dos partes en mí

22 "[...] los hombres temen la muerte como si supieran con certeza que es el más grande de los males, cosa que ignoran. Mas el miedo los incita a hacer malas acciones" (Platón, Apología de Sócrates, 29a y 35a).

${ }^{23}$ De hecho, Platón expresa el principio en forma más débil: los contrarios no pueden encontrarse en la misma cosa al mismo tiempo (436b), aplicado en las páginas siguientes. 
con rasgos distintos. Empleando este método, Platón llega a reconocer tres partes del alma: la razón, la parte pasional (thumos), y la parte que tiene deseos. La contradicción en la conducta (incluso la conducta verbal) es un síntoma de conflicto entre las facultades o partes del alma, que, como homunculi, tienen metas e intereses distintos. Por contraste, el modelo socrático determinará que tengo creencias incompatibles, por ejemplo que el comer (en esta situación) no es bueno, y que el comer (en la misma situación) es bueno. Según el modelo platónico, la contradicción en la conducta resulta del conflicto de las partes del alma; según el modelo socrático, resulta del conflicto de creencias, que son proposiciones incompatibles. Las distintas implicaciones de los dos modelos muestran, por cierto, que la teoría de Sócrates es incompatible con la de Platón, por lo menos con la psicología moral del Platón maduro. Pero Platón critica la psicología moral de Sócrates incluso en los diálogos tempranos, aparentemente indicando su descontento por largo tiempo con las asunciones socráticas. ${ }^{24}$ El descontento de Platón establece con una seguridad mayor de la que pudiera lograr su acuerdo, el hecho de que la teoría que tratamos es la de Sócrates, no la de Platón.

\section{Aplicación del modelo}

Un número de rasgos importantes de la teoría y la práctica morales de Sócrates pueden, quiero afirmar, derivarse del modelo. De hecho, creo que el modelo puede dar cabida a la mayor parte de lo que es distintivo de la ética socrática, incluso lo que es más extraño. En lo que sigue trataré de identificar algunos rasgos que adquieren sentido cuando son comprendidos a la luz de la psicología moral de Sócrates.

1. El élenchos es un método de mejoramiento moral. El único método de Sócrates parece ser el élenchos, su método de hacer preguntas y examinar las respuestas. Usualmente, Sócrates pide una definición de una virtud; hace una serie de preguntas subsidiarias, a veces para aclarar la definición, a veces persiguiendo asuntos que aparentemente no están relacionados con ella. Al final, descubre una contradicción entre la definición propuesta y otras proposiciones que ha hecho el interlocutor. Lo que es misterioso es comprender cómo este método más bien cerebral o intelectual puede tener conexión con el

${ }^{24}$ Véase los puntos (2) y (3) de la sección I. Supongo que las definiciones de la templanza del Cármides, de $164 \mathrm{~d}$ en adelante, son exploraciones del intelectualismo socrático, y que todas son derrotadas. Un argumento, en $174 \mathrm{~b}-\mathrm{d}$, reaparece en Repúbli$c a$, VI, 505b-c, como base para rechazar la tesis de que la virtud es conocimiento. Véase también el rechazo de una definición socrática del valor en Laques, 195a y ss. 
compromiso y con la práctica de la conducta moral. Sin embargo, según el modelo, el método es perfectamente racional. El sentido del élenchos es eliminar las creencias falsas que entran en conflicto con un entendimiento correcto de lo que es bueno o malo. Aunque un solo examen elénctico no puede cambiar la vida de uno, hay esperanza de que, según el modelo proposicional, la práctica continuada del examen puede permitir que uno se deshaga de las falsedades. Por lo menos, ser refutado puede indicar al individuo que sus creencias acerca del bien y el mal no son consistentes y requieren ulterior examen.

El élenchos depende de las opiniones del interlocutor, no de las de quien interroga o las de una tercera persona, por ejemplo un experto reconocido. Así, podemos deducir el principio socrático de la sinceridad ("di lo que quieres decir"), según el cual el interlocutor debe dar la que considera su propia opinión. El llamado método mayéutico del Teeteto viola este requisito por invitar al contestador a que explore las opiniones de los expertos, las cuales pueden o no reflejar sus propias creencias. ${ }^{25} \mathrm{El}$ que interroga debe poner a prueba la consistencia del conjunto de las creencias del interlocutor; introducir otros conjuntos de creencias solamente puede confundir el proceso, y puede invalidarlo completamente.

Según el modelo actual, el élenchos es una práctica de terapia individual, de manera análoga a la psicoterapia. El que responde tiene que revelar sus propias concepciones para poder aclararlas. Según la teoría de Freud, sin embargo, lo que uno expone son las reacciones más profundas a las experiencias tempranas, y al menos en parte ventila sus relaciones emocionales. Según la teoría socrática, en cambio, lo que uno expone son solamente proposiciones, para considerar su consistencia con otras proposiciones. Sócrates practica una terapia lógica. Así, las emociones y experiencias no desempeñan ningún papel en el proceso. No obstante, como en la psicoterapia, la terapia lógica se puede practicar solamente "uno a uno", y tiene un aspecto subjetivo: únicamente se pueden discutir las creencias de una sola persona. Además, no hay ningún atajo para ocuparse de las creencias: el que pregunta no puede, llegado a un cierto punto del examen, simplemente declarar que unas creencias del interlocutor son falsas, o que otras creencias distintas de las aceptadas por el interlocutor son verdaderas. Actuar así sería vano, porque no tendría ningún impacto en el alma del interlocutor. Solamente introduciría una creencia más en el conjunto de creencias del contestador, y una creencia que sería inconsistente con las creencias previas. La creencia falsa tiene que ser elimina-

${ }^{25}$ G. Vlastos, Socratic Studies. Cambridge, Universidad de Cambridge, 1994, pp. 1314; M. Burnyeat, "Socratic Midwifery, Platonic Inspiration", en Bulletin of the Institute of Classical Studies, núm. 24, 1977, pp. 7-15. 
da antes de que pueda experimentarse algún progreso moral. El examen, al menos el que se practica repetidamente, puede purgar creencias falsas, restaurando la consistencia en el alma del interlocutor.

2. La virtud no se puede enseñar. La conducta moral justa resulta de un conjunto consistente de creencias. Sócrates parece mantener que todo el mundo comparte las creencias verdaderas sobre cuestiones morales. ${ }^{26}$ Si ya contamos con todas las creencias necesarias para el comportamiento moral, no necesitamos aprender más. Lo que necesitamos es eliminar las creencias falsas que interfieren con el ejercicio de nuestras creencias verdaderas. Esta eliminación puede resultar, como hemos visto, de una aplicación del élenchos. El examen, pues, puede proporcionar o mantener la virtud. Sin embargo, no puede proporcionar en nosotros un estado permanente de virtud. Es decir, que el tener éxito en la práctica del élenchos hasta el día de hoy hará consistentes las proposiciones de mi alma, de manera tal que yo actuaré de acuerdo con mis principios, sin ser confundido por principios contradictorios. Pero no hay ninguna garantía de que mañana estaré en este estado. Pues mañana seré bombardeado con declaraciones falsas que presuponen valores espurios, dado que mucha de la gente con la que inevitablemente me asocio está infectada con creencias falsas y valores espurios. Si el día de mañana yo aceptara, aun tácitamente, algunas de sus creencias, estaría abriéndole la puerta a la inconsistencia en mis creencias. De modo que no hay tal cosa como haber logrado la virtud.

Si esto es así, tengo que practicar el élenchos todos los días. Solamente por medio del examen cotidiano de mis creencias puedo estar seguro de que mi propia alma no esté infectada por creencias inconsistentes. Este resultado podría parecerle sorprendente a un intelectualista, pero al mismo tiempo es bienvenido. Pues la implicación del intelectualismo que parece tan difícil aceptar es precisamente que yo puedo alcanzar la virtud de una vez por todas. La experiencia común es que tenemos que ocuparnos de nuestro carácter diariamente. Pero ahora vemos que según el modelo de Sócrates, se sigue la misma consecuencia: en la vida moral no hay escapatoria de la necesidad de una vigilancia diaria. Claro que la clase de vigilancia requerida por el intelectualismo de Sócrates es muy diferente de la requerida por las teorías voluntaristas. Uno debe practicar el examen elénctico, una especie de terapia lógica, en lugar de la autoexhortación. Sin embargo, hay una suerte de requerimiento paralelo para las dos teorías. Y lo que es más importante, podemos ver que para la teoría de Sócrates, igual que para las bien conocidas teorías voluntaristas,

26 Por ejemplo Gorgias, 474a-b, 482a y Apología de Sócrates, 25e-26a, con G. Vlastos, Socratic Studies, pp. 23-25. 
la virtud, o por lo menos el vivir virtuosamente, es más bien un proceso que un producto.

3. El élenchos es benéfico tanto para el que pregunta como para el que responde. Los intérpretes de Sócrates no están de acuerdo acerca del valor del élenchos. Para algunos, por ejemplo, Sócrates es completamente ignorante de la virtud y de cómo alcanzarla, y, por consiguiente, no tiene la seguridad de que su método conducirá a que alguien experimente alguna mejoría. ${ }^{27} \mathrm{En}$ cambio, el modelo proposicional del alma implica que el élenchos tiene valor terapéutico tanto para el que pregunta como para el que contesta. Pues el élenchos es una investigación en común, en la cual quien pregunta tiene la oportunidad de ver confirmadas las proposiciones que él considera consistentes, y de ver refutadas las proposiciones inconsistentes con ellas. En el Gorgias, Sócrates se defiende de la objeción que todo el mundo discreparía con él por desafiar a Polo:

Yo sé cómo obtener un testigo de lo que digo: aquél con quien converso. En cuanto a la mayoría, los paso por alto y trato de ganar un solo voto [... ] Mira, pues, si por tu parte te someterás al examen y contestarás a mis preguntas. Pues creo que tú y yo, y de hecho todos los hombres consideramos que hacer injusticia es peor que sufrirla. ${ }^{28}$

El único testigo que puede confirmar las creencias del que pregunta es quien contesta. Luego Sócrates lanza un reto semejante a Calicles, con una advertencia significativa:

Refútala a ella [a la filosofía] y a su afirmación que yo acabo de defender contra ti, de que cometer injusticia y quedar impune es el peor de todos los males; o, si dejas esta afirmación irrefutada [... ] entonces

27 Richard Kraut, Socrates and the State. Princeton, Universidad de Princeton, 1984, pp. 283-284. "Nada que Sócrates pueda pretender saber podría valer para establecer que posee lo que es más precioso: sabiduría moral" (Thomas C. Brickhouse y Nicholas D. Smith, Plato's Socrates. Oxford, Universidad de Oxford, 1994, p. 71). "El élenchos [...] revela lo que uno realmente cree en el fondo, y simplemente trata esta forma de creencia, sin apología, como conocimiento no-experto [...] El descubrimiento, no la justificación, es el legado positivo del élenchos" (P. Woodruff, "Plato's Early Theory of Knowledge", en S. Everson, ed., Epistemology. Cambridge, Universidad de Cambridge, 1990, p. 81). Véase también A. Nehamas, "Socratic Intellectualism", en Proceedings of the Boston Area Colloquium on Ancient Philosophy 2, 1987, pp. 275-316.

${ }^{28}$ Platón, Gorgias, 474a-b. 
Calicles no estará de acuerdo contigo, Calicles, sino que estará en desacuerdo $^{29}$ contigo durante toda tu vida. ${ }^{30}$

Está claro que la implicación es que la única manera en que el sofista puede ser consistente consigo mismo es aceptando (entre otras cosas) la verdad que hacer injusticia es el peor de los males.

La discusión del método en el Gorgias es más reflexiva que en otros lugares de los diálogos socráticos, pero es consistente con las declaraciones de Sócrates a través de los diálogos. ${ }^{31}$ Por ejemplo, en la Apología, Sócrates pregunta si Méleto piensa que Sócrates hace mal voluntariamente -una posibilidad que excluye la psicología moral de Sócrates. A su asentimiento tácito responde: "Yo no te creo, Méleto, ni pienso que ningún otro te crea tampoco". ${ }^{32}$

En la superficie, Sócrates obviamente no tiene razón. Pero desde el punto de vista de la práctica elénctica de Sócrates, él podría insistir razonablemente en que está en lo cierto. Pues el sentido en el cual todo el mundo estará de acuerdo con Sócrates es el sentido según el cual un examen elénctico resultará en la aceptación de la tesis de Sócrates -el interlocutor afirmará y en este sentido confirmará su tesis. ${ }^{33}$ De manera semejante, en el Protágoras, Sócrates sostiene:

Mantengo esta tesis: que nadie que sea sabio acepta que alguien hace el mal voluntariamente, ni que alguien lleva a cabo voluntariamente actos que son malos y reprobables, sino que [un hombre sabio] comprende perfectamente que todos los que hacen cosas malvadas y reprobables, las hacen involuntariamente. ${ }^{34}$

Probablemente, Sócrates mantendría que cualquiera que no comparta su punto de vista es ipso facto alguien que no es sabio: pues mantener la tesis

29 Diaphonesei, literalmente estar desafinado; evidentemente quiere decir ser lógicamente inconsistente (no había todavía un vocabulario lógico en el tiempo de Platón).

${ }^{30}$ Platón, Gorgias, 482b.

${ }^{31}$ Platón permite que Sócrates se quite la máscara y admita que practica el arte verdadero de la política (512d). Proporciona a Sócrates tesis socráticas que defender (en vez de sólo examinar las tesis de su interlocutores), y termina con un mito apocalíptico, como en algunos diálogos medios. En general, el Gorgias es más polémico y más aseverativo que los otros diálogos socráticos, y parece proporcionar una defensa sistemática de una posición socrática.

${ }^{32}$ Platón, Apología de Sócrates, 25e.

33 Véase G. Vlastos, Socratic Studies, p. 25.

${ }^{34}$ Platón, Protágoras, 345d-e. 
rival lo envolvería en una contradicción consigo mismo, lo que demostraría que no es sabio, es decir: consistente consigo mismo.

4. La educación moral no requiere el castigo. En el Gran Discurso, Protágoras hace hincapié en la familiaridad, la práctica, el entrenamiento, y también en el castigo como medios para inculcar la virtud. ${ }^{35}$ Pero, como le dice a Méleto, si acaso Sócrates ha errado en sus comunicaciones con la juventud, no lo hizo a propósito. ${ }^{36}$ Pues nadie, como ya sabemos por su teoría, hace el mal voluntariamente. Méleto, por consiguiente, debería corregirlo, debería reeducarlo, si Sócrates actúa incorrectamente. Para la teoría socrática, no obstante lo que Sócrates dice en el Gorgias respecto de la necesidad del castigo, ${ }^{37}$ realmente no hay lugar para el castigo. El único método de mejoramiento moral es el élenchos. Pudiera parecer que éste es una especie de castigo cuando trae consigo la humillación pública, pero para el que lo pone en práctica, no lo es. Cuando mucho, sería una terapia dolorosa, análoga al procedimiento de un médico cuando hace una operación. La razón por la que la terapia es efectiva no es el dolor o la humillación por sí mismas, sino la supresión de las creencias falsas. El paciente se alivia de un objeto dañino y ajeno, cuya presencia le impediría gozar de cabal salud. Ninguno de los factores concomitantes del castigo desempeña ninguna función en el mejoramiento moral del individuo.

5. La educación moral no consiste en la exhortación. La exhortación presupone que la voluntad tiene que escoger entre el bien y el mal; cuando somos tentados por los atractivos del mal, debemos fortalecer la resolución de la voluntad a perseguir el bien. Pero si por naturaleza escogemos lo que es bueno, si, en términos modernos, estamos programados a perseguir el bien, no hay ningún momento en que tengamos que decidir, ninguna crisis moral. Lo único indispensable es comprender cuál sendero es verdaderamente bueno, o, en el caso de resultados desventajosos, cuál es el menor de dos males. Por consiguiente, la exhortación moral no tiene razón de ser. Y esto nos trae de nuevo a la declaración de Sócrates de que pasa todo su tiempo exhortando a los atenienses a que se comporten moralmente. El problema que notamos al empezar es que nunca vemos que Sócrates realmente haga esto. Luego, si no hace exhortaciones morales, ni tiene justificación teórica para hacerlo, ¿por qué dice que lo hace? Posiblemente esté explicando su misión de mejorar la conducta moral de los atenienses en términos que éstos puedan entender. Proyecta sus esfuerzos hacia el mejoramiento moral con el lenguaje del discurso moral cotidiano. Su práctica del examen elénctico corresponde a una

\footnotetext{
35 Ibid., 324a-c.

36 Platón, Apología de Sócrates, 26 a.

${ }^{37}$ Platón, Gorgias, 478e-479e.
} 
vida dedicada a exhortar a la gente a que cumpla con sus deberes y elija el bien. Pero por supuesto que el examen elénctico no ejemplifica la exhortación, sino más bien la reemplaza como método de mejoramiento moral.

6. Practicar el élenchos es el mayor bien que uno puede hacer. Tal vez la declaración más célebre de Sócrates en la Apología sea ésta: "La vida sin examen no es digna de ser vivida para el hombre". ${ }^{38}$

El modelo proposicional del alma proporciona una justificación teórica obvia para esta declaración. Sin un examen elénctico, el alma está llena de contradicciones y los actos del individuo son contradictorios e irracionales. Pero si uno examina su alma, y su vida, que son la misma tarea, uno puede vivir una vida de excelencia moral.

Todavía más decisivas son las palabras que proceden la declaración ya citada: "Éste resulta ser el mayor bien para el hombre, discutir cada día acerca de la virtud y las otras cosas acerca de las cuales me escucháis al conversar y examinarme a mí mismo y a los demás". 39

La famosa declaración de Sócrates acerca de la vida sin examen es el miembro negativo de un equilibrado par de declaraciones, del cual la mitad positiva dice que la conversación filosófica es el mayor bien para la vida humana. Esta conversación consiste en hablar acerca de la virtud -la materia del élenchosy en dirigir un examen -la forma del élenchos. A fin que el élenchos sea efectivo como terapia, es necesario que uno lo practique cada día, como Sócrates lo afirma aquí, y que la práctica beneficie tanto al que pregunta como al que contesta. El método será el mayor bien porque hace al practicante moralmente virtuoso, y porque al menos aproxima al que contesta a la virtud moral. Libre de contradicciones, quien practique el élenchos discernirá correctamente lo que es bueno de lo que es malo, y escogerá el bien.

\section{Conclusión}

Platón presenta en Sócrates una teoría que es radicalmente diferente de las teorías morales que han dominado el pensamiento moderno. En vez de una teoría en la cual la voluntad escoge entre fines que le parecen deseables, Sócrates nos da una teoría en la cual el intelecto escoge entre el bien y el mal (prefiriendo siempre el bien), o entre bienes mayores y menores (eligiendo siempre los mayores), o entre males mayores y menores (escogiendo siempre los menores). Esta teoría ha parecido imposible de defender porque no está

\footnotetext{
38 Platón, Apología de Sócrates, 38 a.

${ }^{39}$ Idem.
} 
de acuerdo con nuestra experiencia: saber lo que es bueno o malo no parece ser suficiente, ni tampoco parece que un sencillo proceso de aprendizaje pueda producir la conducta moral. Como hemos visto, la teoría de Sócrates es más compleja y más sutil de lo que usualmente se cree. No mantiene que el conocimiento del bien y el mal se pueda enseñar, ni cree que se pueda lograr como estado permanente de cognición. $\mathrm{Al}$ asumir que el alma es una serie de proposiciones, podemos entender cómo sus declaraciones enigmáticas contribuyen a una teoría coherente. La conducta moral surge de un alma que funciona a base de creencias consistentes, en la cual las proposiciones incompatibles no producen resultados contradictorios. Para lograr que la creencia sea consistente, el agente moral tiene que practicar el élenchos, y practicarlo diariamente para eliminar u obstruir el crecimiento de creencias falsas. La teoría ética de Sócrates es una hazaña extraordinaria, construida a base de una psicología sencilla, pero mundana y altamente original. Aunque no es probable que consiga gran popularidad hoy en día, ofrece una alternativa atractiva a los enfoques modernos de la ética. 